\title{
Predation by the Nonnative Tokay Gecko, Gekko gecko (Linnaeus 1758), on the native Carolina Wren (Thryothorus ludovicianus) and nonnative Cuban Treefrog (Osteopilus septentrionalis) in Florida, USA
}

Kenneth L. Krysko ${ }^{1}$ and William B. Love ${ }^{2}$

${ }^{1}$ Division of Herpetology, Florida Museum of Natural History, University of Florida, Gainesville, Florida 32611, USA (kenneyk@ufl.edu) ${ }^{2}$ Blue Chameleon Ventures, 5062 North Bear Court, Apache Junction, Arizona 85120, USA (bill@bluechameleon.org)

Photographs by William B. Love

$T^{1}$

The Tokay Gecko, Gekko gecko (Linnaeus 1758), is native to southeastern Asia. It has been introduced to many areas around the world (Kraus 2009), including Florida, USA (Barbour 1931; Krysko et al. 2011a, 2011b). In Florida, it has been intentionally introduced by animal dealers (Meshaka et al. 2004), by residents to control cockroaches in homes (Wilson and Porras 1983), and accidentally via escaped pets.

In southern Florida, Gekko gecko has been documented consuming mostly beetles, roaches, and moths (Meshaka et al. 1997a, 2004a), but it is also known to prey on the Woodslave, Hemidactylus mabouia (Moreau de Jonnès 1818; see Meshaka et al. 2004a) and Eastern Corn Snake, Pantherophis guttatus (Linnaeus 1766; see Love 2000; Fig. 1). Herein, we augment our knowledge regarding the diet of G. gecko in Florida to include the native Carolina Wren, Thryothorus ludovicianus (Latham 1790), and nonnative Cuban Treefrog, Osteopilus septentrionalis (Duméril and Bibron 1841). Photographs of these two new events, as well as for the Pantherophis guttatus (cited above), were deposited as vouchers (UF-Herpetology 150221, 177230-177233; Figs. 1-3) in the Division of Herpetology, Florida Museum of Natural History, University of Florida. All three observations occurred on the side of a house, approximately $0.61 \mathrm{~km}$ southwest of State Road 80 and the Hendry County line, Alva, Lee County (26.70404, -81.56775; WGS84).

Fig. 1. Color rendition of Love's (2000) photograph of a Tokay Gecko (Gekko gecko) preying on a juvenile Eastern Cornsnake (Pantherophis guttatus), UF-Herpetology 177230-177231, in November 1998 in Alva, Lee County, Florida.

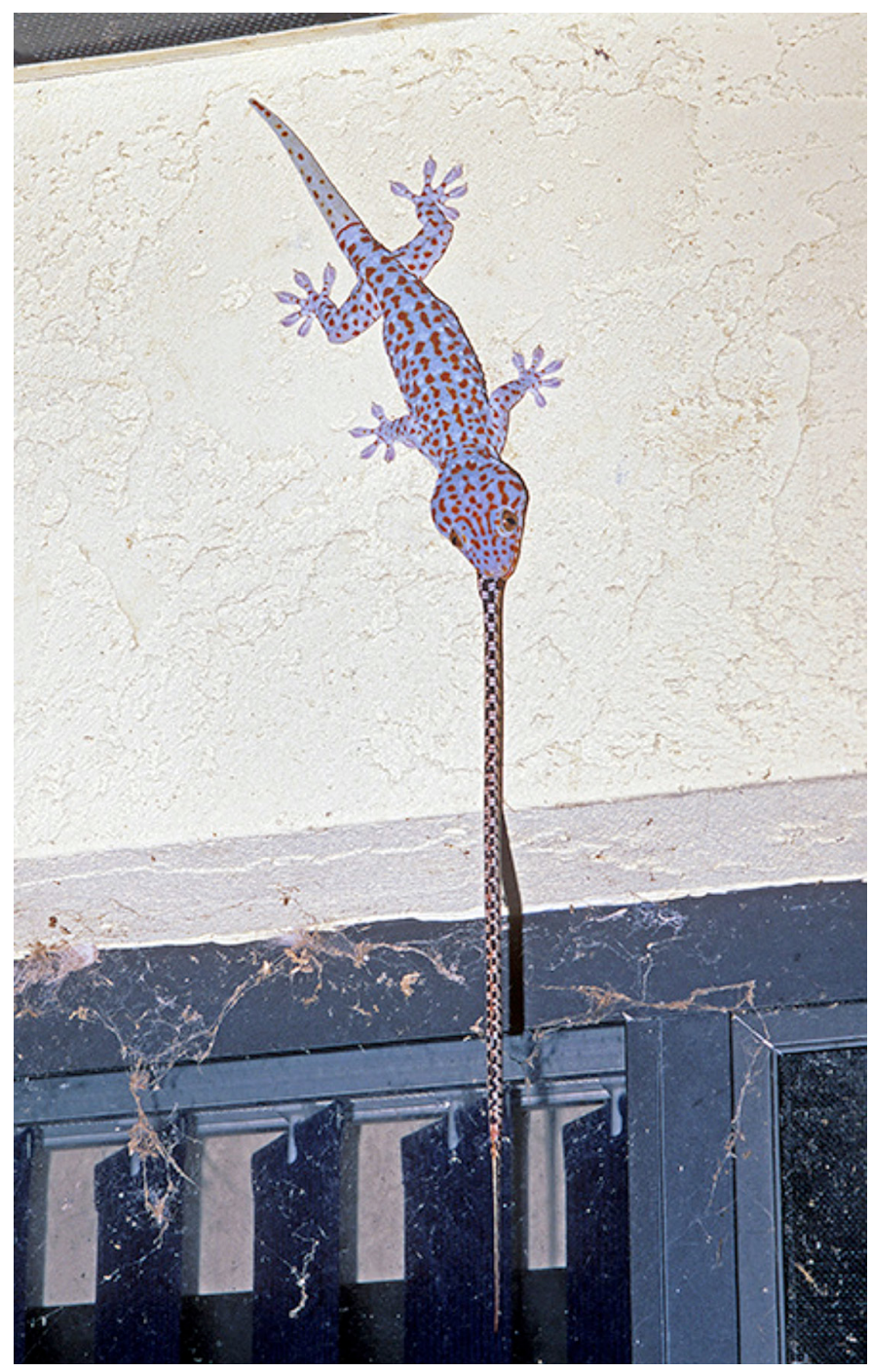




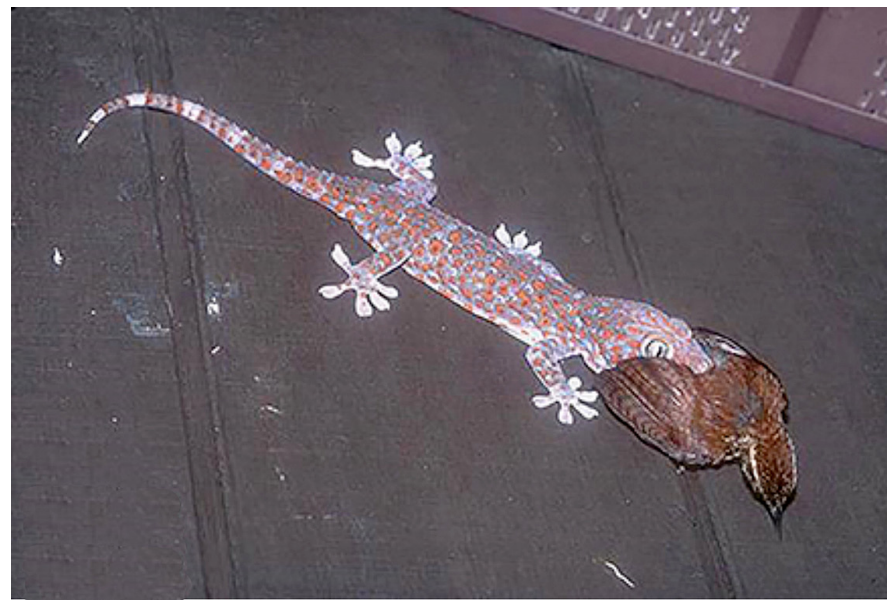

Fig. 2. Tokay Gecko (Gekko gecko) preying on a native Carolina Wren (Thryothorus ludovicianus), UF-Herpetology 150221, during the summer of 2010 in Alva, Lee County, Florida.

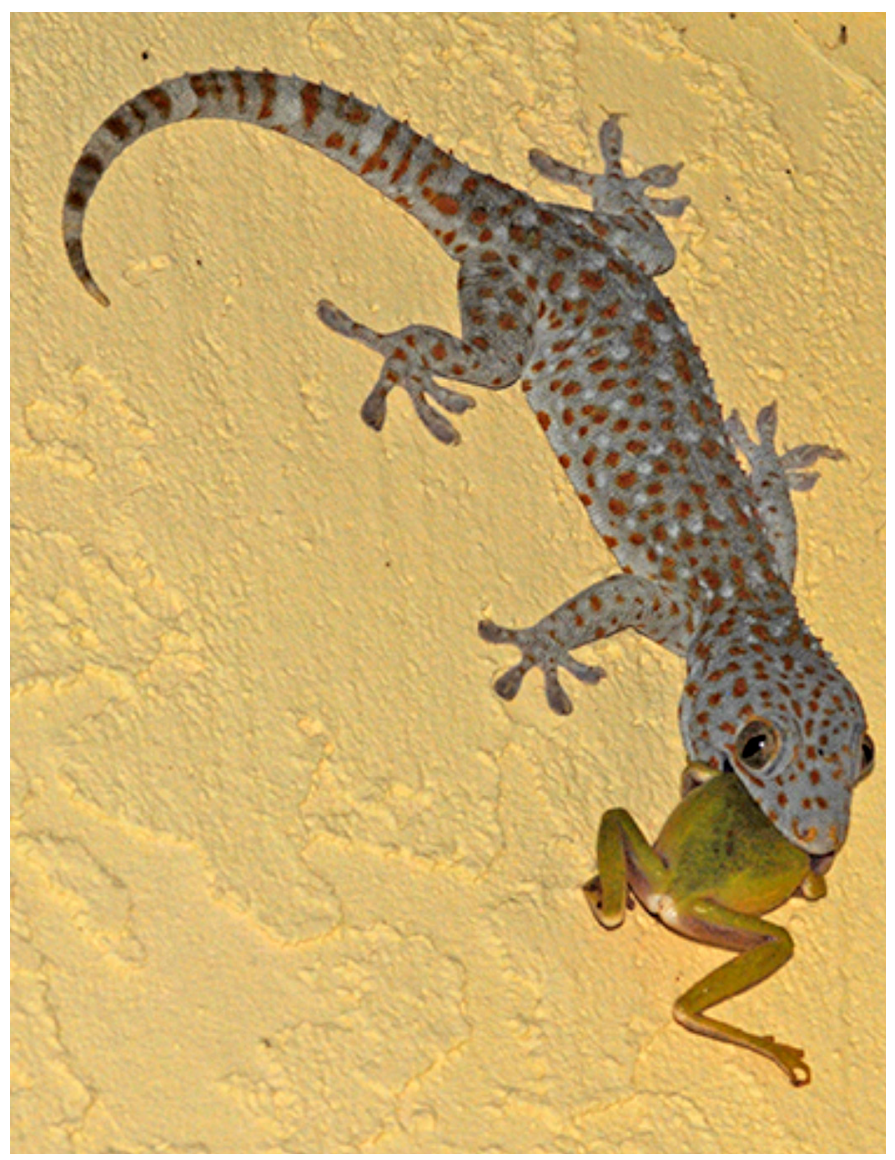

Fig. 3. Tokay Gecko (Gekko gecko) preying on a nonnative Cuban Treefrog (Osteopilus septentrionalis), UF-Herpetology 177232-177233, during the summer of 2009 from Alva, Lee County, Florida.
During summer 2010, an adult Gekko gecko was observed feeding on a Carolina Wren (Thryothorus ludovicianus) just after dark (Fig. 2). The gecko retreated with the bird after the photograph was taken. Although actual ingestion was not observed, no trace of the bird was found on the ground hours later.

During summer 2009, an adult Gekko gecko was observed feeding on a Cuban Treefrog (Osteopilus septentrionalis) at dusk (Fig. 3). The gecko ingested the frog within a few minutes after the photograph was taken. Numerous other individuals of both species were observed under the eaves of the home at the time.

Gekko gecko can grow to $400 \mathrm{~mm}$ TL (Caillabet 2013). Because of its large size, it can consume larger items than most geckos. Despite Osteopilus septentrionalis having highly toxic skin secretions, at least 15 wildlife taxa are known to prey on this frog (see Meshaka 2011). Our data provide the first documentation of Gekko gecko consuming either Thryothorus ludovicianus or Osteopilus septentrionalis.

\section{Acknowledgments}

We thank David W. Steadman for verifying the Carolina Wren, and Paul E. Moler and Michael R. Rochford for verifying the Cuban Treefrog.

\section{Literature Cited}

Barbour, T. 1931. Another introduced frog in North America. Copeia 1931: 140.

Kraus, F. 2009. Alien Reptiles and Amphibians, a Scientific Compendium, and Analysis. Invading Nature: Springer Series in Invasion Biology 4. Springer, Dordrecht, The Netherlands.

Krysko, K.L., J.P. Burgess, M.R. Rochford, C.R. Gillette, D. Cueva, K.M. Enge, L.A. Somma, J.L. Stabile, D.C. Smith, J.A. Wasilewski, G.N. Kieckhefer III, M.C. Granatosky, and S.V. Nielsen. 2011a. Verified non-indigenous amphibians and reptiles in Florida from 1863 through 2010: Outlining the invasion process and identifying invasion pathways and stages. Zootaxa 3028 : $1-64$.

Krysko, K.L., K.M. Enge, and P.E. Moler. 2011b. Atlas of Amphibians and Reptiles in Florida. Final Report, Project Agreement 08013. Florida Fish and Wildlife Conservation Commission, Tallahassee.

Love, W.B. 2000. Gekko gecko (Tokay Gecko). Predation. Herpetological Review 31: 174 .

Meshaka, W.E., Jr. 2011. A runaway train in the making: The exotic amphibians, reptiles, turtles, and crocodilians of Florida. Monograph 1. Herpetological Conservation and Biology 6: 1-101.

Meshaka, W.E., Jr., B.P. Butterfield, and J.B. Hauge. 2004. The Exotic Amphibians and Reptiles of Florida. Krieger Publishing Company, Malabar, Florida.

Meshaka, W.E., Jr., R.M. Clouse, and L. McMahon. 1997. Diet of the Tokay Gecko (Gekko gecko) in southern Florida. Florida Field Naturalist 25: 105107.

Wilson, L.D. and L. Porras. 1983. The Ecological Impact of Man on the South Florida Herpetofauna. University of Kansas Museum of Natural History, Special Publication No. 9, Lawrence. 